\title{
Evaluation of Antimalarial Drug use in Tertiary Care Teaching Hospital
}

\author{
Anushree Shrikant Deshpande ${ }^{1 *}$, Mallappa Hanamantappa Shalavadi ${ }^{2}$, Harshitkumar Bhupendrabhai \\ Patel $^{2}$, Arvind Dayalbhai Vasoya ${ }^{2}$, Rahul Kotwal ${ }^{3}$, Chandrashekhar VM ${ }^{2}$
}

${ }^{1}$ Assistant Professor, Department of Pharmacy Practice, KLE University's College of Pharmacy, Belagavi, Karnataka, INDIA. ${ }^{2}$ Department of Pharmacy Practice, H.S.K College of Pharmacy, Bagalkot, Karnataka, INDIA.

${ }^{3}$ Medical Advisor, Department of Medical Affairs, Macleods Pharmaceuticals Ltd., Andheri East, Mumbai, Maharashtra, INDIA.

\begin{abstract}
Background: Malaria is a major cause of morbidity and mortality in the developing countries. Rational use of antimalarial drugs reduces the development of drug resistance and cost of therapy. Hence, we sought to evaluate the use of antimalarial drugs. Aim: The study was designed to evaluate the use of anti-malarial drugs in in-patient admission of medicine and pediatrics department at tertiary care teaching hospital. Methods: The data was obtained prospectively from 98 patients with antimalarial drugs over a period of 6 months. The evaluation was assessed based on age, pattern of malarial parasite, therapy and rationality of prescription. Results: The demographic details of patients admitted in hospital showed more male patients $(60.52 \%)$ than children's $(19.48 \%)$ and this reflects that the prevalence of the disease was higher among adult patients in this region during the study. Out of 98 patients prescribed with antimalarial drugs, only 46 patients showed malarial infection and 52 patients were diagnosed with non-malarial infection. In this study three drug combination therapy was prescribed more (30.61\%) followed by two drugs combination. Rationality of antimalarial drug prescription was assessed by NVBDCP out of which $45.65 \%$ and $82.69 \%$ were irrational respectively. Conclusion: In this study it was found that inappropriate use of antimalarial drugs was higher among patients with Plasmodium falciparum and non-malarial patients. Cost of therapy was very high and thus it contributed to the economic burden on patients. Irrational prescriptions were high which indicated non-adherence to guidelines. Hence it concludes that educating the health professional for rational drug use as well as reducing the cost of therapy is essential.
\end{abstract}

Key words: Antimalarial, Rationality, Drug interaction, Cost effective analysis.

\section{INTRODUCTION}

Malaria is a tropical disease transmitted by the female Anopheles mosquito of which Anopheles gambiae is the most efficient vector. ${ }^{1}$ It is caused by infection by the protozoan parasite of the genus plasmodium, is a disease of global importance. ${ }^{2}$ Malaria is a major cause of morbidity and mortality in the developing world. ${ }^{3}$ It is a public health problem in more than 90 countries. Each year, between 300 and 500 million new cases are reported worldwide. ${ }^{4}$ The global tally of malaria in 2015 was 212 million cases and 4, 29,000 deaths. According to the report fewer than half of the 91 malaria affected countries and territories are on track to achieve the 2020 milestone of a $40 \%$ reduction in case incidence and mortility. ${ }^{15}$
WHO now recommends that treatment policies for falciparum malaria in all countries experiencing resistance to monotherapies such as chloroquine, sulphadoxinepyrimethamine and amodiaquine, should be combined preferably with those containing an artemisinin derivative. ${ }^{5}$ Artemisinin also known as Qinghaosu and its derivatives are a group of drugs that possess the most rapid action of all current drugs against Plasmodium falciparum malaria. Treatments containing an artemisinin derivative (artemisinin-combination therapies, ACTs) are now standard treatment worldwide for Plasmodium falciparum malaria, artemisinin is a sesquiterpene lactone. ${ }^{6}$
DOI: 10.5530/ijopp.10.3.41

Address for correspondence: Anushree S Deshpande, Assistant Professor Department of Pharmacy Practice,

KLE University's College of Pharmacy, Belagavi-01, Karnataka, INDIA. Phone No: 08792998483 Email Id: anushri4deshpande@ gmail.com

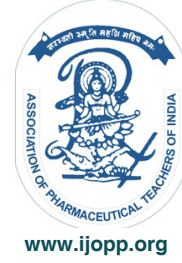


India has the largest population in the world at risk of malaria, with $85 \%$ living in malarious zones. ${ }^{7}$ Around 1.5 million confirmed cases are reported annually by the National Vector Borne Disease Control Programmed (NVBDCP), of which about $50 \%$ are due to Plasmodium falciparum. ${ }^{8}$ In recent studies, chloroquine-resistant Plasmodium falciparum malaria has been observed with increasing frequency across the country. ${ }^{9}$ Karnataka is located in western side of India, in the southern peninsular region. Since many years, the highest incidence in Karnataka were recorded in regions of Bijapur, Bagalkot, Raichur, Kolar, Bellary, Dakshina kannada and Mandya district which together accounted for more than $60 \%$ of malaria cases. ${ }^{14}$ With this above background and Bagalkot is one of endemic city in Karnataka thus this study aims to evaluate antimalarial drugs use in S.N. Medical College and HSK Hospital, Bagalkot with specific aims to assess rationality of utilization of anti-malarial drugs, to assess potential interaction of antimalarial drugs with other prescribed drugs and to evaluate cost of anti-malarial drugs prescribed.

\section{OBJECTIVES}

- To assess rationality of anti-malarial drugs use.

- To assess potential interaction of anti-malarial drugs with other prescribed drugs.

- To evaluate cost of anti-malarial drugs prescribed.

\section{METHODS}

\section{Study Design}

This was a prospective hospital based observational study.

\section{Study Location}

This study was conducted in general medicine and Pediatrics Departments of S.N Medical College and HSK Hospital and Research Center Bagalkot. It is a multispecialty tertiary care teaching hospital with different specialties and super specialties. HSK Hospital provides primary and specialized health care facilities to people in and around Bagalkot district.

\section{Study criteria}

\section{Inclusion criteria}

- Patients diagnosed with malaria.

- Patients of all age group of either sex.

- Patients receiving anti-malarial drugs.

\section{Exclusion criteria}

- Patients attending outpatient department.

\section{Study procedure}

Personal visit made on daily basis to general medicine ward and paediatric wards to identify the patients who were diagnosed with malaria. Patient demographic details like name, age, sex, In Patient Department Number (IPD no), weight was noted in specially designed patient data collection form. Clinical history, diagnosis, laboratory investigations and treatment regimen of the patients and discharge medications were recorded daily in-patient data collection form. Treatment chart of the patients were reviewed daily to evaluate type of treatment regimen. Name of drug, dose, frequency, duration and cost of treatment was noted in patient data collection form. Further data were analysed for the anti-malarial drugs usage according to guidelines for the diagnosis and treatment of malaria (2011). Potential drug-drug interactions in the treatment regimen were assessed using Micromedex-2.0.

\section{Cost benefit analysis}

1. The average number of drug and I.V injection of antimalarial drugs prescribed for patients was calculated by using the below formula

Average number of drugs $=\frac{\text { Total number of drugs }}{\text { Number of patients }}$

I.V. Injection (Percentage $)=\frac{\begin{array}{l}\text { Number of patients } \\ \text { Numberion of patients }\end{array}}{\text { Number }} \times 100$

2. The average drug cost per prescription and percentage drug cost on injection of antimalarial drugs prescribed for patients was calculated by using the below formula:

Average drug cost $/$ prescription $=\frac{\text { Total cost of all drugs prescribed }}{\text { Total number of cases }}$
Cost of injections

Percentage of drug cost of injection $=\frac{\text { prescribed }}{\text { Total drug cost }} \times 100$

\section{RESULTS AND DISCUSSION}

Malaria is one of the major public health problems of the country. Prompt and effective treatment is important for preventing the transmission of malaria. In view of this we studied drug use of antimalarial in malaria patients. Drug use indicator as defined by WHO has provided easy 
and convenient measures to assess optimal drug use in health facilities. A total of 98 subjects were assessed for drug evaluation of antimalarial for 6 months of study period. The socio-demographic details of the study participants are represented in Table 1 and the result shows male predominance $(60.52 \%)$ in antimalarial usage. The antimalarial are prescribed highly in the age group of $31-45$ years $(21.58 \%)$ which was like previous studies conducted in various areas ${ }^{10,11}$ and this reflects that the prevalence of the disease was higher among adult patients in this region during the study. During the study, out of 98 subjects prescribed with antimalarial drugs, 46 subjects showed malarial infection and 52 patients were diagnosed with non-malarial infection and in 46 malarial cases, $78.78 \%$ of patients were serum positive for Plasmodium falciparum and $21.22 \%$ were with Plasmodium vivax and mixed type of infection. This indicated that Plasmodium falciparum is more common in this area of Karnataka for malarial infection. This report was like the previous study. ${ }^{3}$ Data reported in Table 2. The major prescription of antimalarial agents was Artesunate (14.4\%), Artesunate/ Sulfadoxine/Pyrimethamine (19.70\%), Artemether/ Lumefantrine (17.42\%), and Chloroquine $(12.12 \%)$ and others 2 to $8 \%$ were observed. Data reported in Table 3 .

The Artesunate when prescribed alone lead to the development of resistance according to national vector borne disease control programme (NVBDCP).
NVBDCP recommended that Artesunate should be given in combination with Sulfadoxine/Pyrimethamine or lumefantrine. In this study three drug combination therapy was superior $(30.61 \%)$ by two drugs combination. In the combination therapy, almost all contains artemisinin derivatives which was in accord with guidelines for diagnosis and treatment of malaria and a similar study was done previously. ${ }^{13}$ Data reported in Table $4.2 .17 \%$ of prescriptions showed potential drugdrug interaction of artemisinin derivatives in malarial patients and 13.46\% among non-malarial patients. Data reported in Table 5 and 6.

Rationality of antimalarial drug prescription was assessed by NVBDCP. During the study we observed that 46 malarial infection patients were prescribed with antimalarial drugs and out of these $45.65 \%$ were irrational prescriptions and out of 52 non-malarial patients, it was $82.69 \%$. This showed that antimalarial drugs were prescribed more among the non-malarial infection patients. Therefore, there is a great need to educate health care workers. Data reported in Table 7.

After evaluating this study, the prescribing indicators showed $44.879 \%$ of the prescribed I.V. injections increased the cost of prescription as injections are costlier then oral therapy. Not only the drug efficiency but also the cost of the drug is a major component in the drug utilization study. As in our study drug cost on

\begin{tabular}{ccc}
\hline Table 1: Socio-demographic parameters. & \\
\hline Gender & Number of patients & Percentage $(\%)$ \\
\hline Men & 58 & 60.52 \\
Women & 40 & 39.48 \\
\hline Age & Number of patients & Percentage (\%) \\
\hline 0-27 days & 02 & 03.16 \\
\hline 28 days -23 months & 03 & 03.16 \\
02-11 years & 10 & 13.16 \\
12-18 years & 08 & 05.79 \\
18-30 years & 22 & 20.53 \\
31-45 years & 24 & 21.58 \\
46-60 years & 15 & 17.37 \\
$>60$ years & 14 & 15.25 \\
\hline
\end{tabular}

\begin{tabular}{ccc} 
Table 2: Pattern of malaria parasite infection in patient visiting tertiary care hospital. \\
\hline Malaria parasite & Number of prescription & Percentage of prescription \\
\hline Plasmodium falciparum & 27 & $58.69 \%$ \\
Plasmodium vivax & 4 & $08.69 \%$ \\
Mixed & 3 & $6.52 \%$ \\
Clinical malaria & 3 & $6.52 \%$ \\
Complicated malaria & 9 & $19.5 \%$ \\
Total $(\mathrm{n})$ & 46 & $100 \%$ \\
\hline
\end{tabular}




\begin{tabular}{ccc}
\hline Table 3: Antimalarial drugs prescribed for patient visiting tertiary care hospital. \\
\hline Name of drugs & Numbers of prescription & Percentage of prescription (\%) \\
\hline Artesunate & 19 & 14.40 \\
\hline Aretsunate+Pyrimethamine +Sulphadoxine & 26 & 19.70 \\
Artemether/Lumefantrine & 23 & 17.42 \\
Chloroquine phosphate & 16 & 12.12 \\
Doxycycline & 31 & 23.49 \\
Primaquine & 11 & 08.33 \\
Hydroxy chloroquine sulphate & 03 & 02.28 \\
Quinine & 03 & 02.28 \\
\hline
\end{tabular}

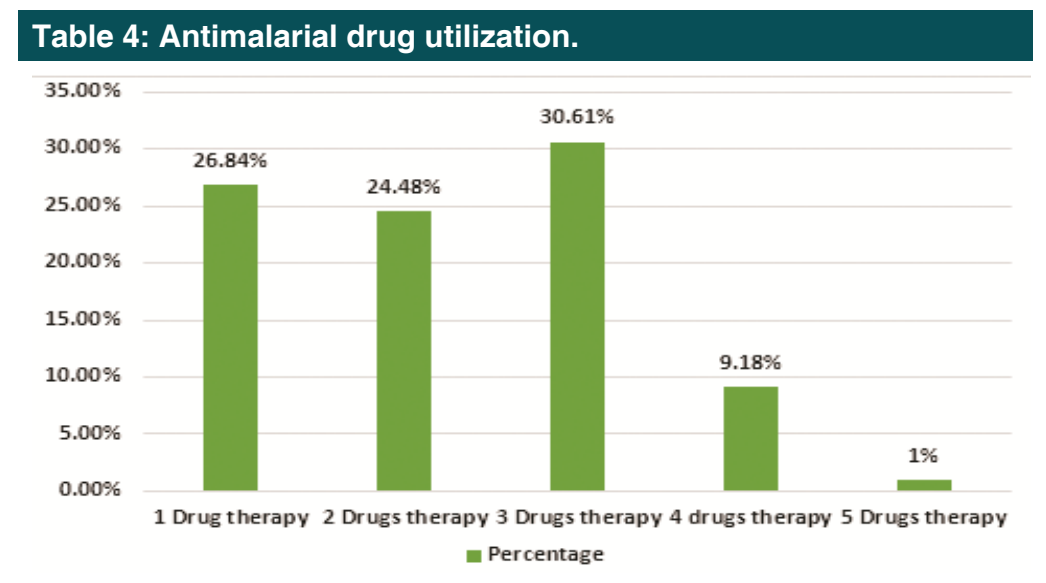

\begin{tabular}{ccc}
\hline $\begin{array}{c}\text { Table 5: Drug interaction found in prescriptions. } \\
\text { Type of Drug interaction }\end{array}$ & Number of drug interaction & Percentage (\%) \\
\hline Major & 16 & 43.24 \\
Moderate & 12 & 32.43 \\
Minor & 06 & 18.92 \\
Contraindication & 03 & 05.41 \\
Total & 37 & 100 \\
\hline
\end{tabular}

Table 6: Drug-drug interaction of artemisnine derivative with other drugs in prescription.

\begin{tabular}{ccc} 
Infection & Drug-drug interactions & Percentage (\%) \\
\hline Malarial cases $(\mathrm{n}=46)$ & 01 & 02.17 \\
Non-malarial cases $(\mathrm{n}=52)$ & 07 & 13.46 \\
\hline
\end{tabular}

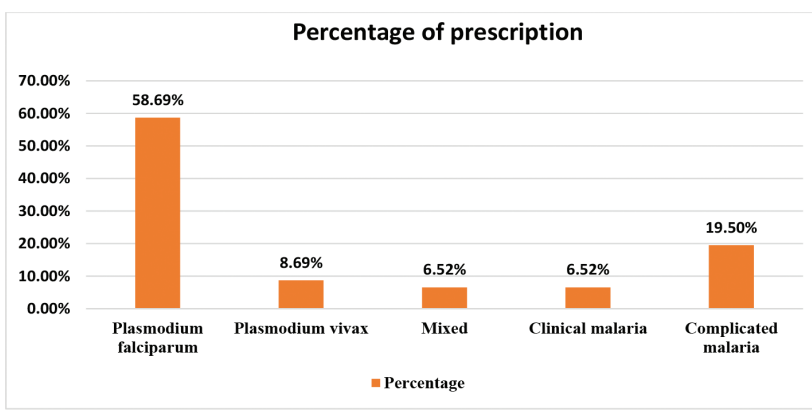

Figure 1: Percentage of prescriptions for individual malarial parasite. 


\begin{tabular}{|c|c|c|c|c|}
\hline \multirow[t]{3}{*}{ Condition } & \multicolumn{4}{|c|}{ Treatment } \\
\hline & \multicolumn{2}{|c|}{ Rational } & \multicolumn{2}{|c|}{ Irrational } \\
\hline & Total & $\%$ & Total & $\%$ \\
\hline Plasmodium vivax & 03 & 12 & 01 & 04.76 \\
\hline Plasmodium falciparum & 13 & 52 & 14 & 66.67 \\
\hline Mixed & 03 & 12 & 00 & 00.00 \\
\hline Clinical malaria & 03 & 12 & 00 & 00.00 \\
\hline Complicated malaria & 03 & 12 & 06 & 28.57 \\
\hline
\end{tabular}

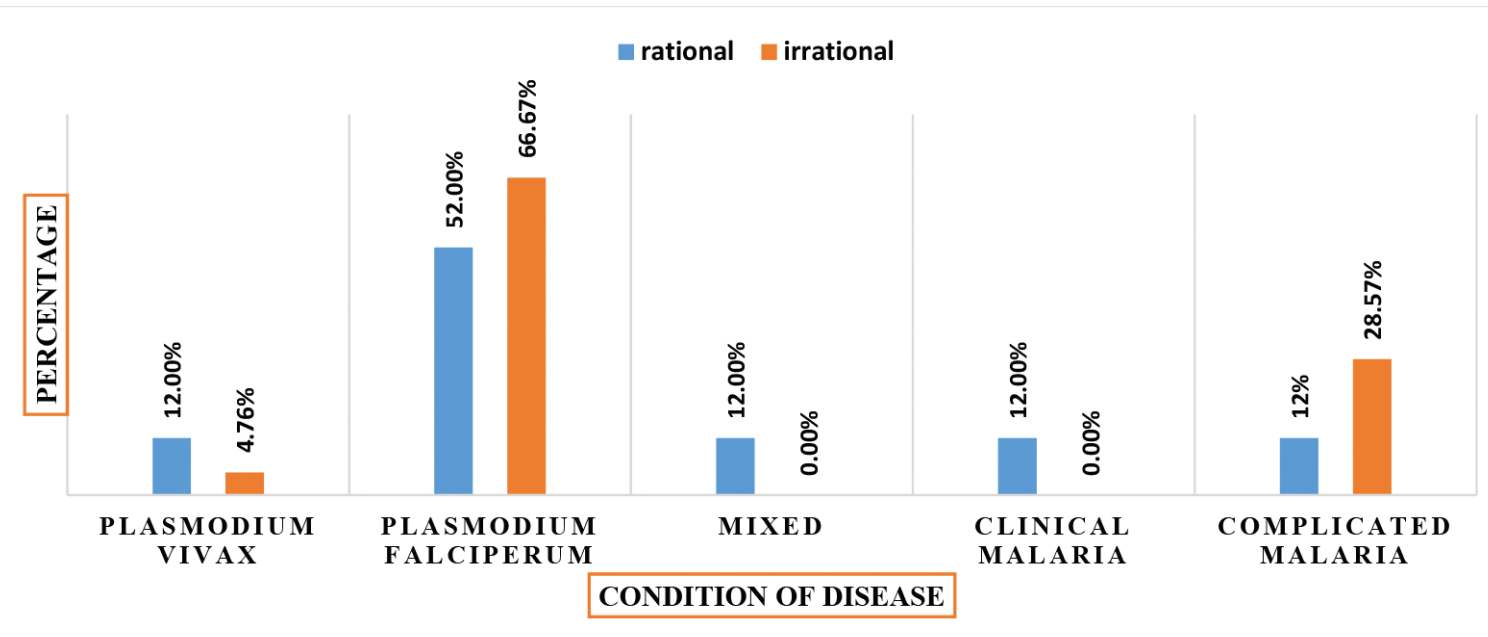

Figure 3: Assessment of rationality of antimalarial drugs.

Table 8: Drug use evaluation of antimalarial drugs
prescribed for patients with help of prescribing indicator.

\begin{tabular}{cc} 
Indicator & Data \\
\hline Average no of drug & 1.42 \\
I.V. injection(percentage) & $44.89 \%$ \\
\hline
\end{tabular}

injection was $86.51 \%$ out of total cost which indicated artemisinin derivatives were used more because these are available as I.V preparations and are much more expensive than conventional antimalarial drugs. This result was comparable with the study done in Gujarat. ${ }^{12}$ Data reported in Table 8 and 9.

\section{CONCLUSION}

In this study it was found that inappropriate use of antimalarial drugs was higher among patients with Plasmodium falciparum and non-malarial patients. The Cost of therapy was very high and thus it contributed to the economic burden on patients. Irrational prescriptions Indian Journal of Pharmacy Practice, Vol 10, Issue 3, Jul-Sep, 2017

\begin{tabular}{|c|c|}
\hline Indicator & Data \\
\hline Average drug cost & 1085.22 Rupees \\
\hline Percentage drug cost on injection & $86.51 \%$ \\
\hline
\end{tabular}

were high which indicted non-adherence to guidelines. Therefore, it concludes that educating the health professional for rational drug use as well as reducing the cost of therapy is essential.

\section{ACKNOWLEDGEMENT}

The authors would like to thank Dr I.S.Muchchandi, Principal, H.S.K College of Pharmacy, Bagalkot. I also thank Principal, SN Medical College and HSK hospital, Bagalkot and all health professionals of general and pediatric department for their constant support and guidance. 


\section{CONFLICT OF INTEREST}

The authors declare no conflict of interest.

\section{ABBREVIATION USED}

AS+SP: artesunate plus sulfadoxine and pyrimethamine; FDC: Fixed Dose Combination; IV: Intra venous; IPD: In patient Department; NVBDCP: National Vector Borne Disease Control Programme; OPD: out patient department; P. Falciparum: Plasmodium falciparum; P. Vivax: Plasmodium Vivax; WHO: World Health Organization; ACT's: Artemisinin combination therapy.

\section{REFERENCES}

1. Oshikoya K. Anti-malarial prescriptions for children presenting with uncomplicated malaria to a teaching hospital in Nigeria after the change of national guidelines for malaria treatment, World J Med Sci. 2007;2(1):49-53.

2. Dass R, Barman H, Duwarah SG, Deka NM, Jain P, Choudhury V. Unusual presentations of malaria in children: an experience from a tertiary care centre in North East India. Indian J Ped. 2010;77(6):655-60.

3. Krungkrai J, Imprasittichai W, Otjungreed S, Pongsabut S, Krungkrai SR. Artemisinin resistance or tolerance in human malaria patients, Asian Pacific. J of Tropical Med, 2010;3(9):748-53.
4. Buabeng KO, Duwiejua M, Dodoo AO, Matowe LK, Enlund H. Self-reported use of anti-malarial drugs and health facility management of malaria in Ghana. Malar J. 2007;6(1):85.

5. Medicines Sans Frontiers ACTNOW to get malaria treatment that works to Africa. MSF Access to Essential Medicines Campaign, Geneva. 2003;2(3):390-3.

6. White NJ. "Assessment of the pharmacodynamic properties of antimalarial drugs invitro". Antimicrob Agents Chemotherapy. 1997;41(7):1413-22.

7. Shah NK, Dhillon GP, Dash AP, Arora U, Meshnick SR, Valecha N. Anti-malarial drug resistance of Plasmodium falciparum in India: changes over time and space, Lancet Infect Dis. 2011;11(1):57-64.

8. Government of India, Guidelines for diagnosis and treatment of malaria. 2011;2.

9. Dellicour S, Tatem AJ, Guerra CA, Snow RW, Ter Kuile FO, Quantifying the number of pregnancies at risk of malaria in 2007: A demographic study, 2010;7(1);e1000221.

10. Costa AD, Bhartiya S, Eltayb A, Nandeswar S, Diwan VK. Patterns of Drug Use in the Public Sector Primary Health Centers of Bhopal District. Pharm World Sci. 2008;30(5):584-9.

11. Lamichhane D, Giri BR, Pathak OK, Panta OB, Sankar PR. Morbidity Profile and Prescribing Patterns among Outpatients in a Teaching Hospital in Western Nepal. McGill J Med. 2006;9(2):126-33.

12. Dhara L, Rina D, Patel CN. Drug utilization study of antimalarial drugs in a tertiary care hospital. 2012;2(4):761-77

13. Alexander ND, Carole F, Alex A. Pattern of drug utilization for treatment of uncomplicated malaria in urban. Ghana following national treatment policy change to artemisinin combinational therapy malaria journal. 2009;8(2):1-8.

14. Talwar AS, Pujar HS, Karnataka. $\mathrm{J}$; Epidemiological situation of malaria in irrigated areas:A case study of Raichur district, Karnataka : 2011;24(2)198-200.

15. The complete World Malaria Report 2016 available at : http://www.who.int/ malaria/ publications/world-malariareport-2016/report/en/ 